\title{
Neoadjuvant therapy for breast cancer
}

\author{
Tumori Journa \\ I-6 \\ (C) Fondazione IRCCS Istituto \\ Nazionale dei Tumori 2019 \\ Article reuse guidelines: \\ sagepub.com/journals-permission \\ DOI: $10.1177 / 0300891619869505$ \\ journals.sagepub.com/home/tmj
}

@SAGE

\author{
Lucia Mangone' (D), Pamela Mancuso', Giovanna Tagliabue², \\ Rosa Angela Filiberti ${ }^{3}$, Giuliano Carrozzi ${ }^{4}$, Silvia lacovacci ${ }^{5}$, \\ Walter Mazzucco 6 , Rosario Tumino ${ }^{7}$, Pamela Minicozzi ${ }^{8}$, \\ Milena Sant ${ }^{8}$ and Paolo Giorgi Rossi'
}

\begin{abstract}
Objective: To evaluate the frequency of neoadjuvant therapy (NT) in women with stage I-III breast cancer in Italy and whether it is influenced by biological characteristics, screening history, and geographic area.

Methods: Data from the High Resolution Study conducted in 7 Italian cancer registries were used; they are a representative sample of incident cancers in the study period (2009-20I3). Included were 3546 women aged <85 years (groups $<50,50-69,70-64$, and 75+) with stage I-III breast cancer at diagnosis who underwent surgery. Women were classified as receiving NT if they received chemotherapy, target therapy, and/or hormone therapy before the first surgical treatment. Logistic models were built to test the association with biological and contextual variables.

Results: Only $8.2 \%$ of women ( 290 cases) underwent NT; the treatment decreases with increasing age (I $4.5 \%$ in age $<50$ and $2.2 \%$ in age $75+$ ), is more frequent in women with negative receptors (14.8\%), HER2-positive (I5.7\%), and triplenegative (I5.6\%). The multivariable analysis showed the probability of receiving NT is higher in stage III (odds ratio [OR] 3.83; 95\% confidence interval [Cl] 2.83-5.I8), luminal B (OR I.87; 95\% Cl I.27-2.76), triple-negatives (OR I.88; 95\% Cl I.I5-3.08), and in symptomatic cancers (OR I.98; 95\% Cl I.I3-3.48). Use of NT varied among geographic areas: Reggio Emilia had the highest rates (OR 2.29; $95 \% \mathrm{Cl}$ I.37-3.82) while Palermo had the lowest (OR 0.4I; 95\% Cl 0.24-0.68).

Conclusions: The use of NT in ltaly is limited and variable. There are no signs of greater use in hospitals with more advanced care.
\end{abstract}

\section{Keywords}

Breast cancer, neoadjuvant therapy, multidisciplinary

Date received: 28 February 2019; revised: 03 May 2019; accepted: 20 June 2019

\section{Introduction}

In 2017, 52,300 new cases of breast cancer (BC) were diagnosed in Italy, accounting for $14 \%$ of all malignant tumors and $30 \%$ of those in female patients. ${ }^{1} \mathrm{BC}$ is the most common cancer in women in all age groups: it accounts for $41 \%$ of cancer diagnoses before age 50, 35\% between 50 and 69 years, and $22 \%$ in women aged $\geqslant 70$. Tumor stage ${ }^{2}$ at diagnosis is a strong determinant of survival: in the regions where an organized screening program is active, most of the cases are diagnosed at an early stage, resulting in better survival. ${ }^{3}$

In general, great attention is paid to the diagnosis and treatment of early forms (in situ tumors and stage I tumors); early diagnosis is possible owing to mammographic screening and good outcomes owing to treatment. ${ }^{4,5}$ Attention to metastatic forms (stage IV) is also
'Epidemiology Unit, Azienda Unità Sanitaria Locale-IRCCS Reggio Emilia, Reggio Emilia, Italy

${ }^{2}$ Analytical Epidemiology and Health Impact Unit, Research Department, Fondazione IRCCS Istituto Nazionale dei Tumori, Milan, Italy

${ }^{3}$ RTR Liguria, IRCCS AOU SM-IST, Liguria, Italy

${ }^{4}$ Department of Public Health, Local Health Unit, Modena, Italy ${ }^{5}$ Latina Cancer Registry, Lazio, Italy

${ }^{6}$ Department of Health Promotion and of Maternal and Childhood Sciences, University of Palermo, Palermo, Italy

${ }^{7}$ Histopathology Department and Cancer Registry, Provincial Health Authority, ASP Ragusa, Ragusa, Italy

${ }^{8}$ Analytical Epidemiology and Health Impact Unit, Research Department, Fondazione IRCCS Istituto Nazionale dei Tumori, Milan, Italy

Corresponding author:

Lucia Mangone, Epidemiology Unit, AUSL of Reggio Emilia, IRCCS, Via Amendola 2, 42I22, Reggio Emilia 42I22, Italy.

Email: mangone.lucia@ausl.re.it 
Table I. Characteristics of the population in the areas covered by cancer registries and presence of organized screening.

\begin{tabular}{|c|c|c|c|c|c|c|c|}
\hline Registry & Varese & Genova & Reggio Emilia & Modena & Latina & Palermo & Ragusa \\
\hline Total population ${ }^{\mathrm{a}}$ & 871,000 & 854,000 & 518,000 & 686,000 & 545,000 & $1,243,000$ & 308,000 \\
\hline$\%$ Living in cities $>100,000^{a}$ & 0 & 68.5 & 31.4 & 26.1 & 21.6 & 52.9 & 0 \\
\hline $\begin{array}{l}\text { Centers with more than } 150 \text { new cases per year } \\
\text { in the area }\end{array}$ & Yes & Yes & Yes & Yes & No & Yes & No \\
\hline Incidence ASR (Europe) ${ }^{\mathrm{b}}$ & 120.5 & 118.8 & 122.6 & 130.4 & 101.7 & 100.9 & 88.9 \\
\hline \multicolumn{8}{|l|}{ Stage, \% } \\
\hline I & 52.7 & 58.4 & 55.4 & 63.3 & 46.9 & 34.5 & 41.8 \\
\hline II & 31.6 & 25.5 & 28.3 & 23.0 & 30.7 & 39.0 & 35.4 \\
\hline III & 15.0 & 16.1 & 16.3 & 11.7 & 17.1 & 23.8 & 22.6 \\
\hline Unknown & 0.7 & 0.0 & 0.0 & 2.0 & 5.3 & 2.7 & 0.2 \\
\hline 5-year survival, \% & 87 & 87 & 89 & 90 & 84 & 85 & 81 \\
\hline \multicolumn{8}{|l|}{ Screening } \\
\hline Year of activation ${ }^{c}$ & 2001 & 2000 & 1994 & 1995 & 2001 & 2005 & $2009 \mathrm{~d}$ \\
\hline Invitation coverage, \%c & 91.7 & 30.9 & $\sim 100$ & $\sim 100$ & 50.2 & 54.3 & 59.7 \\
\hline \% Test coverage in organized screeningc & 51.6 & 19.6 & 73.3 & 59.6 & 26.4 & 24.2 & 24.7 \\
\hline Total coverage including opportunistic screeningb & 85.8 & 74.7 & 85.1 & 86.9 & 67.5 & 60.8 & 47.3 \\
\hline
\end{tabular}

aData from the National Institute of Statistics (ISTAT), I January 2012.

bData from ITACAN, Tumori in Italia versione 2.0.

cData from the National Centre for Screening Monitoring.

dActive since 1994, but inactive in the 2004-2009 period.

ASR: Age-standardized rate

increasing as the availability of biological drugs has significantly improved the prognosis of these neoplasms. ${ }^{6}$ Describing locally advanced forms (tumor-node-metastasis [TNM] stage II and III) is more complex as these include different tumor sizes and different levels of regional lymph node involvement, with a large spectrum of possible treatments.

For stages II and III, the therapeutic objectives of neoadjuvant therapy (NT) are to obtain a low probability of relapse, increasing the possibility of curative surgery, and at the same time, reducing the invasiveness of the same. For this reason, several trials have evaluated the efficacy of neoadjuvant (presurgical) therapies for nonmetastatic tumors that present characteristics making an immediate surgical approach difficult or at risk of failure. ${ }^{7,8}$ Currently, the guidelines include the option of NT or hormone therapy for large tumors, i.e. stage II (T2, N0), and for locally advanced stages, i.e. IIIA, IIIB, and IIIC..$^{8-10}$

With respect to conventional adjuvant treatments, the neoadjuvant approach significantly modifies the therapeutic and diagnostic pathway, changing therapy timing, surgical modalities, therapeutic objectives, diagnostic tools for monitoring response to treatment, and prognosis. $8,11,12$ It is therefore useful to quantify the use of NT across disease stages and settings and along care pathways. At present, however, there are few publications on the diffusion of $\mathrm{NT},{ }^{13}$ and these few show wide variations depending on the type of institution that is caring for the patient.

The objective of the study is to evaluate the use of NT in women with locally advanced BC.

\section{Methods}

For this project, the data of the High Resolution Study, collected by Italian population cancer registries (CRs) and centralized at the National Cancer Institute of Milan as a part of a large European study, were used. ${ }^{14}$ The study includes BC cases from 7 CRs: 4 in northern Italy (Genoa, Varese, Reggio Emilia, and Modena), 1 in central Italy (Latina), and 2 in southern Italy (Palermo and Ragusa).

Table 1 provides a description of the population in the areas covered by the registries, the presence of oncology screening, and specialized reference centers (more than 150 cases per year). The $4 \mathrm{CRs}$ in northern Italy have the highest incidence of BC (range 118.8-130.4 cases per $100,000)$ but also have the highest cancer screening coverage $(74.7 \%-86.9 \%)$, resulting in higher 5 -year survival rates $(87 \%-90 \%)$. The Latina Cancer Registry (central Italy) and those of Palermo and Ragusa (southern Italy) report the lowest incidence of BC (Age-standardized rate (European standard population) $88.9-101.7 \times 100,000$ ) but also the lowest survival rates $(81 \%-85 \%)$.

The study includes all incident cases in 2009-2013 in areas covered by CRs of women aged 15-84 with infiltrating $\mathrm{BC}$ stages I-III who underwent surgery. Ages were divided into 4 groups. Excluded were in situ tumors, metastatic tumors, women aged $\geqslant 85$ years, and those with Paget disease. Receptor status (positive/negative), HER2 (luminal A, luminal B, HER2-positive, triple-negative), morphology (ductal, lobular, mixed ductal-lobular, mucinous), grade $(1,2,3)$, and screening history (screendetected, symptomatic) were analyzed. 
Table 2. Number of cases and \% distribution of patient and cancer characteristics by type of neoadjuvant therapy.

\begin{tabular}{|c|c|c|c|c|c|c|c|c|}
\hline & \multicolumn{2}{|l|}{ Total } & \multicolumn{2}{|c|}{$\begin{array}{l}\text { Neoadjuvant } \\
\text { chemotherapy }\end{array}$} & \multicolumn{2}{|c|}{$\begin{array}{l}\text { Neoadjuvant } \\
\text { endocrine therapy }\end{array}$} & \multicolumn{2}{|c|}{$\begin{array}{l}\text { No neoadjuvant } \\
\text { therapy }\end{array}$} \\
\hline & $\mathrm{n}$ & $\%$ & $\mathrm{n}$ & $\%$ & $\mathrm{n}$ & $\%$ & $\mathrm{n}$ & $\%$ \\
\hline Overall & 3546 & & 290 & 8.2 & 25 & 0.7 & 3231 & 91.1 \\
\hline \multicolumn{9}{|l|}{ Age, y } \\
\hline$<50$ & 904 & 25.5 & $|3|$ & 14.5 & 2 & 0.2 & 771 & 85.3 \\
\hline $50-69$ & 1675 & 47.2 & 130 & 7.8 & 10 & 0.6 & 1535 & 91.6 \\
\hline $70-74$ & 433 & 12.2 & 17 & 3.9 & 4 & 0.9 & 412 & 95.2 \\
\hline $75-84$ & 534 & 15.1 & 12 & 2.2 & 9 & 1.7 & 513 & 96.1 \\
\hline \multicolumn{9}{|l|}{ Stage } \\
\hline 1 & 1774 & 50 & 60 & 3.4 & 16 & 0.9 & 1698 & 95.7 \\
\hline II & 1083 & 30.5 & 76 & 7 & 5 & 0.5 & 1002 & 92.5 \\
\hline III & 623 & 17.6 & 138 & 22.2 & 4 & 0.6 & 481 & 77.2 \\
\hline Unknown & 66 & 1.9 & 16 & 24.2 & 0 & 0 & 50 & 75.8 \\
\hline \multicolumn{9}{|l|}{ HR summary } \\
\hline Positive & 3048 & 86 & 221 & 7.3 & 25 & 0.8 & 2802 & 91.9 \\
\hline Negative & 384 & 10.8 & 57 & 14.8 & 0 & 0 & 327 & 85.2 \\
\hline Unknown & 114 & 3.2 & 12 & 10.5 & 0 & 0 & 102 & 89.5 \\
\hline \multicolumn{9}{|l|}{ Subtype } \\
\hline Luminal A & 2448 & 69 & $|5|$ & 6.2 & 25 & I & 2272 & 92.8 \\
\hline Luminal B & 389 & II & 61 & 15.7 & 0 & 0 & 328 & 84.3 \\
\hline HER2 + nonluminal & 127 & 3.6 & 18 & 14.2 & 0 & 0 & 109 & 85.8 \\
\hline Triple-negative & 212 & 6 & 33 & 15.6 & 0 & 0 & 179 & 84.4 \\
\hline Unknown & 370 & 10.4 & 27 & 7.3 & 0 & 0 & 343 & 92.7 \\
\hline \multicolumn{9}{|l|}{ Morphology } \\
\hline Ductal & 2770 & 78.1 & 242 & 8.7 & 21 & 0.8 & 2507 & 90.5 \\
\hline Lobular & 352 & 9.9 & 22 & 6.3 & 2 & 0.6 & 328 & 93.2 \\
\hline Mixed & 164 & 4.6 & 6 & 3.7 & $\mathrm{I}$ & 0.6 & 157 & 95.7 \\
\hline Mucinous & 81 & 2.3 & 4 & 4.9 & I & 1.2 & 76 & 93.8 \\
\hline NOS & 179 & 5 & 16 & 8.9 & 0 & 0 & 163 & 91.1 \\
\hline \multicolumn{9}{|l|}{ Grading } \\
\hline I & 312 & 8.8 & 3 & I & 5 & 1.6 & 304 & 97.4 \\
\hline 2 & 1859 & 52.4 & 106 & 5.7 & 17 & 0.9 & 1736 & 93.4 \\
\hline 3 & 1187 & 33.5 & 139 & 11.7 & 3 & 0.3 & 1045 & 88 \\
\hline Unknown & 188 & 5.3 & 42 & 22.3 & 0 & 0 & 146 & 77.7 \\
\hline \multicolumn{9}{|l|}{ Registry } \\
\hline Genova & 517 & 14.6 & 32 & 6.2 & 20 & 3.9 & 465 & 89.9 \\
\hline Latina & 655 & 18.5 & 64 & 9.8 & 1 & 0.2 & 590 & 90.1 \\
\hline Modena & 564 & 15.9 & 57 & 10.1 & 2 & 0.4 & 505 & 89.5 \\
\hline Palermo & 592 & 16.7 & 37 & 6.3 & 0 & 0 & 555 & 93.8 \\
\hline Ragusa & 438 & 12.4 & 37 & 8.4 & 0 & 0 & 401 & 91.6 \\
\hline Reggio Emilia & 368 & 10.4 & 40 & 10.9 & 2 & 0.5 & 326 & 88.6 \\
\hline Varese & 412 & 11.6 & 23 & 5.6 & 0 & 0 & 389 & 94.4 \\
\hline \multicolumn{9}{|l|}{ Screening history } \\
\hline Screen-detected & 1003 & 28.3 & 36 & 3.6 & 10 & 1 & 957 & 95.4 \\
\hline Symptomatic tumor & 1539 & 43.4 & 179 & 11.6 & 13 & 0.8 & 1347 & 87.5 \\
\hline Unknown & 1004 & 28.3 & 75 & 7.5 & 2 & 0.2 & 927 & 92.3 \\
\hline
\end{tabular}

HR: hormone receptor; NOS: not otherwise specified.

For all variables examined, the status of unknown was taken into consideration.

Multivariable logistic regression models were built to estimate the odds of receiving neoadjuvant treatment, with 95\% confidence intervals (CIs), adjusted for registry and screening history. The models were adjusted for age at diagnosis, stage grouping (stage I was excluded because the proportion of neoadjuvant was too low), and tumor subtype. All statistical analyses were performed with STATA.13 software.

\section{Results}

Table 2 describes the characteristics of the 3546 patients included in this study. Most of the sample (1675 women, $47.2 \%$ ) were aged 50-69 years, the mammography 
Table 3. Number of cases and \% distribution of adjuvant or neoadjuvant therapy by type of surgery.

\begin{tabular}{|c|c|c|c|c|c|c|}
\hline & \multicolumn{2}{|c|}{ Conservative surgery } & \multicolumn{2}{|c|}{ Mastectomy } & \multicolumn{2}{|l|}{ Total } \\
\hline & $\mathrm{n}$ & $\%$ & $\mathrm{n}$ & $\%$ & $\mathrm{n}$ & $\%$ \\
\hline \multicolumn{6}{|l|}{ chemotherapy } & 100 \\
\hline Not done & 1326 & 50 & 281 & 31.5 & 1607 & 45.3 \\
\hline Neoadjuvant & 122 & 4.6 & 168 & 18.8 & 290 & 8.2 \\
\hline Adjuvant & 828 & 31.2 & 320 & 35.9 & I I48 & 32.4 \\
\hline Unknown & 378 & 14.2 & 123 & 13.8 & 501 & 14.1 \\
\hline \multicolumn{7}{|c|}{ Endocrine therapy } \\
\hline Not done & 498 & 18.8 & 181 & 20.3 & 679 & 19.1 \\
\hline Neoadjuvant & 35 & 1.3 & 38 & 4.3 & 73 & 2.1 \\
\hline Adjuvant & 1114 & 42 & 343 & 38.5 & 1457 & $4 I .1$ \\
\hline Unknown & 1007 & 37.9 & 330 & 37 & 1337 & 37.7 \\
\hline \multicolumn{7}{|l|}{ Radiotherapy } \\
\hline Not done & 206 & 7.8 & 507 & 56.8 & 713 & 20.1 \\
\hline Neoadjuvant & 55 & 2.1 & 4 & 0.4 & 59 & 1.7 \\
\hline Adjuvant & 2102 & 79.2 & 242 & 27.1 & 2344 & 66.1 \\
\hline Unknown & 291 & 11 & 139 & 15.6 & 430 & 12.1 \\
\hline \multicolumn{7}{|l|}{ Target therapy } \\
\hline Not done & 1775 & 66.9 & 570 & 63.9 & 2345 & 66.1 \\
\hline Neoadjuvant & 12 & 0.5 & 22 & 2.5 & 34 & I \\
\hline Adjuvant & 124 & 4.7 & 57 & 6.4 & 181 & 5.1 \\
\hline Unknown & 743 & 28 & 243 & 27.2 & 986 & 27.8 \\
\hline
\end{tabular}

screening target population. Fifty percent of the women had stage I cancer, most with positive receptors ( $86 \%)$, and $69 \%$ with molecular subtype luminal A (positive receptor, HER2-negative). The most common morphology was ductal $(78.1 \%)$, the most frequent grade was $2(52.4 \%)$, and tumor status, symptomatic $(43.4 \%)$. The percentage of cases per CR varied from $10.4 \%$ in Reggio Emilia to $18.5 \%$ in Latina.

Regarding treatment, overall only $8.2 \%$ of women (290 cases) underwent NT; this treatment was less frequent with increasing age (14.5\% in younger women and $2.2 \%$ in elderly women) but increased with increasing stage and grade. It was more frequent in women with negative receptors (14.8\%), with HER2-positive receptors $(15.7 \%)$, and in those who were triple-negative (15.6\%). There were no great differences in terms of morphology, while in terms of screening status, those with symptomatic BC underwent more treatment $(11.6 \%)$ than did those who were screen-detected (3.6\%). Only $0.7 \%$ of women ( 25 cases) received adjuvant hormone therapy; most were older, luminal A, mucinous morphology, grade 1 , resident in Genova, and screen-detected.

Women who underwent mastectomy (Table 3) received more adjuvant therapy than did those who underwent breast-conserving surgery, whether it was chemotherapy $(18.8 \%$ vs $4.6 \%)$, endocrine therapy $(4.3 \%$ vs $1.3 \%)$, or target therapy $(2.5 \%$ vs $0.5 \%)$. As far as radiotherapy is concerned, NT was more frequent among women undergoing breast-conserving surgery than among those undergoing mastectomy $(2.1 \%$ vs $0.4 \%$, respectively).
Finally, multivariable analysis (Table 4) showed the odds of receiving NT decreases with increasing age. Women with stage III BC were significantly more likely to receive NT (odds ratio [OR] 3.83; 95\% CI 2.83-5.18) than those with stage II; the probability was highest for the unknown stage (OR 5.03; 95\% CI 2.52-10.03). Women with luminal B tumor were more likely to receive NT (OR 1.87; 95\% CI 1.27-2.76) than luminal A. Triplenegatives were also significantly more likely (OR 1.88; 95\% CI 1.15-3.08) to receive NT.

Mixed ductal-lobular carcinoma carried a lower significant OR of receiving NT (OR 0.35; CI 0.14-0.89). Grading was not associated with the odds of receiving NT, except for the category unknown (OR 8.86; 95\% CI 2.47-31.83).

Among the CRs, only Reggio Emilia shows a high probability of receiving NT (OR 2.29; 95\% CI 1.37-3.82), unlike the other CRs in northern Italy. Palermo shows a lower OR of receiving NT (OR 0.41; 95\% CI 0.24-0.68), as does Ragusa, although with nonsignificant values.

\section{Discussion}

The use of NT was investigated in this study using data from 7 Italian CRs, which includes more than 3500 patients with BC diagnosed in the 2009-2013 period. NT was generally infrequent and concentrated in stage III and among young women; it usually consisted of chemotherapy, while endocrine therapy alone was rare. Positive receptors and HER2-positive and triple-negative subtypes were associated with greater use of NT. 
Table 4. Odds ratios (ORs) of receiving neoadjuvant therapy for women diagnosed with locally advanced breast cancer in 2009-20I 3 in Italy.

\begin{tabular}{|c|c|c|c|c|}
\hline & $\begin{array}{l}\text { Number } \\
\text { of cases }^{\mathrm{a}}\end{array}$ & $\mathrm{OR}^{\mathrm{b}}$ & $p$ & $95 \% \mathrm{Cl}$ \\
\hline \multicolumn{5}{|l|}{ Age, y } \\
\hline$<50$ (ref) & 503 & I & & \\
\hline $50-69$ & 748 & 0.60 & 0.00 & $0.44-0.82$ \\
\hline $70-74$ & 214 & 0.25 & 0.00 & $0.14-0.46$ \\
\hline $75-84$ & 307 & 0.21 & 0.00 & $0.12-0.36$ \\
\hline \multicolumn{5}{|l|}{ Stage } \\
\hline II (ref) & 1083 & I & & \\
\hline III & 623 & 3.83 & 0.00 & $2.83-5.18$ \\
\hline Unknown & 66 & 5.03 & 0.00 & $2.52-10.03$ \\
\hline \multicolumn{5}{|l|}{ Subtype } \\
\hline Luminal A (ref) & 1146 & I & & \\
\hline Luminal B & 231 & 1.87 & 0.00 & $1.27-2.76$ \\
\hline HER2 + nonluminal & 77 & 1.20 & 0.58 & $0.63-2.31$ \\
\hline Triple-negative & 129 & 1.88 & 0.01 & $1.15-3.08$ \\
\hline Unknown & 189 & 0.59 & 0.07 & $0.33-1.05$ \\
\hline \multicolumn{5}{|l|}{ Morphology } \\
\hline Ductal (ref) & 1346 & I & & \\
\hline Lobular & 189 & 0.82 & 0.44 & $0.49-1.36$ \\
\hline Mixed & 98 & 0.35 & 0.03 & $0.14-0.89$ \\
\hline Mucinous & 35 & 2.01 & 0.18 & $0.72-5.6 \mathrm{I}$ \\
\hline NOS & 104 & 0.88 & 0.69 & $0.46-1.67$ \\
\hline \multicolumn{5}{|l|}{ Grading } \\
\hline I (ref) & 70 & 1 & & \\
\hline 2 & 847 & 2.74 & 0.10 & $0.82-9.12$ \\
\hline 3 & 738 & 2.69 & 0.11 & $0.80-9.05$ \\
\hline Unknown & 117 & 8.86 & 0.00 & $2.47-31.83$ \\
\hline \multicolumn{5}{|l|}{ Registry } \\
\hline Latina (ref) & 348 & I & & \\
\hline Genova & 215 & 1.43 & 0.17 & $0.86-2.38$ \\
\hline Modena & 207 & 1.16 & 0.58 & $0.69-1.95$ \\
\hline Palermo & 388 & 0.41 & 0.00 & $0.24-0.68$ \\
\hline Ragusa & 255 & 0.82 & 0.46 & $0.49-1.38$ \\
\hline Reggio Emilia & 164 & 2.29 & 0.00 & I.37-3.82 \\
\hline Varese & 195 & 0.77 & 0.37 & $0.43-1.37$ \\
\hline \multicolumn{5}{|l|}{ Screening history ${ }^{c}$} \\
\hline Screen-detected (ref) & 190 & I & & \\
\hline Symptomatic tumor & 297 & 1.98 & 0.02 & I.13-3.48 \\
\hline Unknown & 91 & I.II & 0.80 & $0.48-2.56$ \\
\hline
\end{tabular}

aStage I excluded

bAdjusted for age, stage, and subtype.

cSelected women age 50-69 and excluded Palermo cancer registry.

A total of $8.2 \%$ of women received NT; these values are very low compared to those of other studies, ranging from $20 \%{ }^{15,16}$ to over $60 \%$ in some US centers, ${ }^{13}$ yet similar to those reported in a recent survey conducted in Italy $(9.7 \%){ }^{17}$

Women are almost $40 \%$ less likely to receive neoadjuvant treatment after age 50 , and $80 \%$ after age 70 , as shown in other studies. ${ }^{13,18}$
Stage is the most important determinant in the treatment of BC. Seven percent of women with stage II cancer and $22 \%$ with stage III received NT; these percentages are lower than those reported in the literature. ${ }^{12}$ Despite its not being indicated, stage I also received a small percentage of NT (3.4\%), as reported in other studies. ${ }^{19}$

The multivariate analysis confirmed that the probability of receiving NT increased 3.8 times in stage III (compared to stage II). The same value was observed in another study only for stage IIIA ${ }^{13}$; in stages IIIB and IIIC, the probability tends to decrease. The Mougalian et al. study ${ }^{18}$ also confirmed a similar trend for stage IIIB but much less so for IIIC.

NT is more frequent in tumors with negative receptors $(14.8 \%)$, less than the $23.5 \%$ reported by Mougalian et al. ${ }^{18}$ The multivariate analysis confirmed higher values for subtype luminal B (OR 1.87) and for triple-negative (OR 1.88); Mohiuddin et al. ${ }^{13}$ reports similar values (OR 1.50 and 1.70 , respectively). NT is less frequent in lobular morphology (OR 0.82) and in mixed morphology (0.35), in line with what Mohiuddin et al. ${ }^{13}$ reported. A positive correlation for grading was found only for unknown forms (OR 8.86), while nonsignificant excesses were found for grades 2 and 3, unlike what other studies have reported. ${ }^{18}$

Reggio Emilia (northern Italy) presented the highest use of NT (OR 2.29). These levels were not seen in neighboring areas such as Modena, despite having a similar healthcare organization and facilities. It should also be noted that Reggio Emilia has a high 5-year survival rate (89\%) for BC, screening coverage at almost $100 \%$, and organized screening participation among the highest in Italy $(73.3 \%)$.

A novel finding of this study is that an increase in NT was observed in symptomatic women and with an unknown screening status, compared to screen-detected, in those provinces where a mammogram screening program has been present for many years. This could be partially due to a residual confounding in the stage: stage II screen-detected cancers are smaller than clinically detected cancers ${ }^{20}$ and they are more frequently resectable at diagnosis, thus not needing NT.

Although not completely comparable, it is clear that Italy had a lower level of NT use in the period under study than did the United States in the same period. One possible explanation for the low tendency of administering NT is that quality of life, treatment delay, progression risk, organization difficulties, and patient compliance were considered obstacles to treatment. ${ }^{17}$ Cultural issues can influence the choice, as can women's awareness. ${ }^{21}$ In the literature, there is a tendency toward reduced NT if women move from academic centers to centers with $>500$ or with $100-500$ interventions per year. ${ }^{13}$ This is not seen in Italy, however; NT use remains very low even in areas covered by top university centers (Modena, Genova, Palermo).

In the same period, in the United States, there was a clear time trend and greater use of NT in larger centers; in Italy, there were no signs of more frequent use in centers 
with more advanced care. Thus, the picture does not forecast an increase in neoadjuvant use in Italy in the near future. This is important for decision-makers because the use of NT implies different resource consumption, particularly for imaging monitoring of treatment response, usually performed with magnetic resonance imaging, as well as a different organizational approach.

\section{Conclusions}

Although the CRs in Italy are not distributed evenly, they are nevertheless able to guarantee a coherent collection of data according to international standards. The use of NT in Italy is limited $(8.2 \%)$, higher in young women, stage III, with negative receptors, HER2 + , and triple-negative. There is a wide geographical variability, not related to the presence of specialized centers. The use of computed tomography should be recommended to patients when indicated.

\section{Acknowledgements}

The authors thank the participating cancer registries for collecting and preparing the data as part of their role in cancer control.

\section{Declaration of conflicting interest}

The authors declare that there is no conflict of interest.

\section{Funding}

This work was carried out in the framework of HIGHCARE: High-resolution project on prognosis and care of cancer patients (PI Milena Sant), supported in part by ERA-NET in the framework of the call on "Translational research on tertiary prevention in cancer patients" (TRANSCAN), with funding from Ministry of Health, Italy; Research Foundation Flanders (FWO), Belgium; Institut National du Cancer, France; Federal Ministry of Education and Research (BMBF), Germany; Naradowe Centrum Badań i Rozwoju, Poland; Ministry of Education, Science and Sport (MIZS), Slovenia; and Instituto de Salud Carlos III, Spain.

\section{ORCID iD}

Lucia Mangone iD https://orcid.org/0000-0003-4850-2678

\section{References}

1. AIOM, AIRTUM, and Fondazione AIOM. I Numeri del Cancro in Italia 2017: Il Pensiero Scientifico Editore. Roma: AIOM, AIRTUM, Fondazione AIOM; 2017.

2. TNM Classification of Malignant Tumors, 7th edition. Hoboken, NJ: Blackwell Publishing; 2010.

3. Coviello V, Buzzoni C, Fusco M, et al; AIRTUM Working Group. Survival of cancer patients in Italy. Epidemiol Prev 2017; 41 (Suppl 1): 1-244.

4. Plevritis SK, Munoz D, Kurian AW, et al. Association of screening and treatment with breast cancer mortality by molecular subtype in US women, 2000-2012. JAMA 2018; 319: $154-164$
5. Broeders M, Moss S, Nyström L, et al; EUROSCREEN Working Group. The impact of mammographic screening on breast cancer mortality in Europe: a review of observational studies. J Med Screen 2012; 19 (Suppl 1): 14-25.

6. Crocetti E, Gori S, and Falcini F. Metastatic breast cancers: estimates for Italy. Tumori 2018; 104: 116-120.

7. Cortazar P, Zhang L, Untch M, et al. Pathological complete response and long-term clinical benefit in breast cancer: the CTNeoBC pooled analysis. Lancet 2014; 384: 164-172.

8. Senkus E, Kyriakides S, Ohno S, et al; ESMO Guidelines Committee. Primary breast cancer: ESMO Clinical Practice Guidelines for diagnosis, treatment and follow-up. Ann Oncol 2015; 26 (Suppl 5): v8-v30.

9. NCCN. Clinical Practice Guidelines in Oncology, Breast Cancer, Version 1. Fort Washington, PA: NCCN; 2018.

10. Associazione Italiana di Oncologia Medica. Linee Guida Neoplasie della Mammella, Edizione 2017. Milan: Associazione Italiana di Oncologia Medica; 2017.

11. Perry N, Broeders M, de Wolf C, Törnberg S, Holland R, and von Karsa L. European guidelines for quality assurance in breast cancer screening and diagnosis; fourth edition, summary document. Ann Oncol 2008; 19: 614-622.

12. EUSOMA Secretariat. The Requirements of a Specialist Breast Unit: EUSOMA. Milan: EUSOMA; 2000.

13. Mohiuddin JJ, Deal AM, Carey LA, et al. Neoadjuvant systemic therapy use for younger patients with breast cancer treated in different types of cancer centers across the United States. J Am Coll Surg 2016; 223: 717-728.

14. European High Resolution Studies, http://www.hrstudies.eu (accessed 15 October, 2018).

15. Fisher B, Brown A, Mamounas E, et al. Effect of preoperative chemotherapy on local-regional disease in women with operable breast cancer: findings from National Surgical Adjuvant Breast and Bowel Project B-18. J Clin Oncol 1997; 15: 2483-2493.

16. van der Hage JA, van de Velde CJ, et al. Preoperative chemotherapy in primary operable breast cancer: results from the European Organization for Research and Treatment of Cancer trial 10902. J Clin Oncol 2001; 19: 4224-4237.

17. Vicini E, Invento A, Cuoghi M, et al; Italian Society of Surgical Oncology (SICO) Breast Oncoteam. Neoadjuvant systemic treatment for breast cancer in Italy: The Italian Society of Surgical Oncology (SICO) Breast Oncoteam survey. Eur J Surg Oncol 2018; 44: 1157-1163.

18. Mougalian SS, Soulos PR, Killelea BK, et al. Use of neoadjuvant chemotherapy for patients with stage I to III breast cancer in the United States. Cancer 2015; 121: 2544-2552.

19. Clifton K, Gutierrez-Barrera A, Ma J, et al. Adjuvant versus neoadjuvant chemotherapy in triple-negative breast cancer patients with BRCA mutations. Breast Cancer Res Treat 2018; 170: 101-109.

20. Turchetti D, Mangone L, Negri R, et al. Changes in breast cancer incidence and stage distribution in Modena, Italy: the effect of a mammographic screening program. Cancer Causes Control 2002; 13: 729-734.

21. Zdenkowski N, Butow P, Spillane A, et al; Australia and New Zealand Breast Cancer Trials Group. Single-arm longitudinal study to evaluate a decision aid for women offered neoadjuvant systemic therapy for operable breast cancer. $J$ Natl Compr Canc Netw 2018; 16: 378-385. 